\title{
Psicologia Social do Protesto: Um Panorama Teórico a partir da Realidade Brasileira
}

\author{
Leandro Amorim Rosa ${ }^{1}$ \\ ${ }^{1}$ Universidade Federal do Acre, \\ AC, Brasil.
}

\author{
Bert Klandermans ${ }^{2}$ \\ ${ }^{2}$ Vrije Universiteit Amsterdam, \\ Holanda do Norte, Holanda.
}

\begin{abstract}
Resumo: Este artigo objetiva apresentar as principais contribuições da psicologia social do protesto articulando tal proposta a ações coletivas e movimentos sociais brasileiros. A psicologia social do protesto tem como foco de análise o comportamento social dos indivíduos e sua questão central é o entendimento da razão pela qual as pessoas participam ou não de protestos. Suas origens remetem à dimensão psicossocial das teorias clássicas de movimentos sociais: teoria do colapso social; teoria da mobilização de recursos; teoria do processo político; e teoria dos novos movimentos sociais. São identificados três grandes motivos para a participação dos indivíduos em movimentos sociais e protestos: instrumentalidade; identidade; expressividade e emoções. A partir desses motivos é realizada uma análise que aborda a dimensão dos sujeitos (lado da demanda), a dimensão dos movimentos e organizações (lado da oferta) e a articulação entre elas (mobilização). Além de apresentar a teoria, o texto busca ilustrar proposições da psicologia social do protesto por meio de elementos da realidade política brasileira. Entende-se que a psicologia social do protesto pode contribuir para o entendimento e a ação em movimentos sociais no contexto brasileiro e latino-americano instrumentalizando acadêmicos, psicólogas e militantes.
\end{abstract}

Palavras-chave: Movimento social, Psicologia, Participação política, Ação coletiva.

\section{Social Psychology of Protest: A Theoretical Panorama Based on Brazilian Reality}

\begin{abstract}
This article aims to present the main principles of the social psychology of protest articulating this proposal with collective actions and social movements in Brazil. The social psychology of protest aims to analyze the individuals' social behavior and its central question is understanding the reasons why people participate or not in protests. Its origins go back to the psychosocial dimension of the classic theories of social movements: societal breakdown theories; resource mobilization theory; political process theory; and new social movements theory. We identified three main motives for the participation of individuals in social movements and protests: instrumentality, identity, and expressiveness and emotions. From these motives we made an analysis that addresses the dimension of the subjects (the demand-side), the dimension of the movements and organizations (supply-side) and the articulation between them (mobilization). In addition to presenting the theory, the text seeks to illustrate propositions of social psychology of protest by using elements of the Brazilian political reality. We understand that the social psychology of protest can contribute to the understanding and action in social movements in the Brazilian and Latin American context by equipping academics, psychologists, and activists.
\end{abstract}

Keywords: Social movement, Psychology, Political participation, Collective action. 


\title{
Psicología Social de la Protesta: Un Panorama Teórico desde la Realidad Brasileña
}

\begin{abstract}
Resumen: Este artículo tiene como objetivo presentar las principales contribuciones de la psicología social de la protesta, articulándolas a las acciones colectivas y los movimientos sociales brasileños. La psicología social de la protesta se centra en el análisis del comportamiento social de los individuos y su eje principal es la comprensión de por qué las personas participan o no en las protestas. Sus orígenes se refieren a la dimensión psicosocial de las teorías clásicas de los movimientos sociales: teoría del colapso social; teoría de movilización de recursos; teoría del proceso político; y teoría de nuevos movimientos sociales. Se identifican tres razones principales para la participación de individuos en movimientos sociales y protestas: instrumentalidad; identidad; expresividad y emociones. Se realiza un análisis que aborda la dimensión de los sujetos (lado de la demanda), la dimensión de los movimientos y las organizaciones (lado de la oferta) y la articulación entre ellos (movilización). Además de presentar la teoría, este texto pretende ilustrar proposiciones de la psicología social de la protesta con elementos de la realidad política brasileña. Se entiende que la psicología social de la protesta puede contribuir a la comprensión y la acción en los movimientos sociales en el contexto brasileño y latinoamericano, equipando académicos, psicólogos y activistas.
\end{abstract}

Palabras clave: Movimiento social, Psicología, Participación política, Acción colectiva.

\section{Introdução}

Os estudos acadêmicos sobre movimentos sociais e protestos têm uma história de mais de um século (Tarrow, 2009). No decorrer desse período, as propostas conceituais e analíticas transformaram-se significativamente e assumiram um caráter interdisciplinar. Sociologia, ciências políticas, história, antropologia e psicologia estão entre as disciplinas que objetivam pensar sobre tais fenômenos (Roggeband \& Klandermans, 2017).

Assim como outros campos acadêmicos, a psicologia social comporta diversas escolas e diferentes abordagens. O presente trabalho terá como foco a chamada psicologia social do protesto, proposta elaborada e desenvolvida pelo grupo de pesquisa liderado pelo professor Klandermans. Tal grupo, sediado na Vrije Universiteit Amsterdam, desenvolve estudos psicossociais sobre participação política e movimentos sociais desde os anos 1970. A psicologia social do protesto visa fornecer contribuições ao campo a partir de seu foco específico: o comportamento social dos indivíduos. Ainda que não tenha caráter ortodoxo, as principais raízes teóricas e epistemológicas da abordagem remetem à psicologia social cognitiva (Ostrom, 1984).
"Por qual razão algumas pessoas participam e outras não?". Essa é a pergunta fundante da psicologia social do protesto em seus estudos sobre movimentos sociais. Entender os elementos e processos que acarretam a participação dos sujeitos é o objetivo que perpassa toda a abordagem, que toma o indivíduo como unidade de análise e se utiliza predominantemente de variáveis subjetivas (Van Stekelenburg \& Klandermans, 2010). Os estudos em psicologia social têm como premissa que vivemos em um mundo percebido, ou seja, respondemos ao ambiente de acordo com a forma como o percebemos e o interpretamos. Em um mesmo contexto, pessoas diferentes pensam, sentem e agem de forma diversa, e tais diferenças de percepção em muito se devem à inserção social dos sujeitos. Buscar entender porque pessoas em situações aparentemente muito semelhantes optam por engajar-se politicamente ou não é a pedra angular da psicologia social do protesto.

O presente texto definirá movimentos sociais em consonância com Tarrow, que escreve a partir dos trabalhos de Charles Tilly. Segundo Tarrow (2009, p. 21), movimentos sociais são "desafios coletivos baseados em objetivos comuns e solidariedade social numa interação sustentada com as elites, opositores e autoridades". Por sua vez, protestos são formas de ação 
coletiva definidos como "qualquer ocupação temporária por várias pessoas de um espaço aberto, público ou privado, que diretamente ou indiretamente inclui a expressão de opiniões políticas"' (Fillieule, 1997, p. 44, tradução nossa). A partir das definições apresentadas, entende-se que protestos podem ser tidos como pertencentes ao repertório de ação de movimentos sociais.

Desde 2013-e suas Jornadas de Junho (Harvey, 2013; Pinto, 2017) -, o Brasil tem experienciado um período significativo de movimentos e protestos: demonstrações contrárias à realização da copa do mundo de 2014; processo de impeachment da presidenta Dilma Rousseff; ocupações estudantis; demonstrações contrárias à gestão de Michel Temer; greve dos caminhoneiros; atos favoráveis e contrários à campanha do então candidato à presidência Jair M. Bolsonaro, entre outros. Entender a dinâmica que envolve mobilizações como estas é de grande importância no atual cenário político nacional. Certamente as ciências sociais contribuem fundamentalmente para o entendimento desses fenômenos, entretanto, a área da psicologia social e política tem também desenvolvido relevante trabalho sobre tais temáticas (Silva \& Corrêa, 2015).

Dessa forma, propomos, por meio do presente trabalho, abordar os principais conceitos e propostas que têm sido desenvolvidos no campo da psicologia social do protesto. Objetivamos com isso contribuir para a discussão e entendimento de processos de participação política em movimentos sociais brasileiros, assim como subsidiar possíveis ações de psicólogas(os) e militantes de movimentos democráticos, promotores de cidadania e direitos humanos. Metodologicamente, o texto é estruturado de forma a apresentar a psicologia social do protesto e ilustrar suas proposições a partir de elementos da realidade política brasileira. Importante ressaltar que o foco do artigo não é analisar as várias situações abordadas, mas sim utilizá-las como casos que potencializem o entendimento da teoria apresentada. Assim, optou-se por recorrer a uma maior gama de exemplos vinculados a diferentes cenários políticos. Entendemos que tal abordagem impossibilita que os exemplos sejam discutidos e analisados em profundidade, porém, a diversidade dos casos visa evidenciar as contribuições que a teoria pode fornecer em diferentes contextos.

\section{Teorias dos movimentos sociais}

A partir do final do século XIX, pesquisadores começam a propor explicações para o entendimento de manifestações e movimentos de massa que ocorriam naquele período. Um dos pioneiros nesse campo foi Le Bon (1954), que propõe a chamada psicologia das massas. Segundo o pensador francês, os indivíduos em grupo perderiam sua racionalidade e se tornariam impulsivos e manipuláveis. Juntos a Le Bon, outros autores viriam também compor a escola que aglutinaria as chamadas teorias do colapso social² (Blumer, 1969; Gurr, 1970; Hoffer, 1951; Kornhauser, 1959; Smelser, 1971; Toch, 1966). Ainda que de maneiras e níveis de complexidade diversos, tais autores defendiam que as mobilizações e protestos se davam em razão de mudanças sociais e do colapso dos vínculos e arranjos sociais associados a tais mudanças. Segundo essas teorias, as queixas que emergem em momentos de mudança social seriam elemento central para o entendimento da participação em protestos.

Ao focar nas queixas, as teorias do colapso social possibilitaram o desenvolvimento de uma dimensão psicossocial nos estudos da participação política. Propostas como a teoria da privação relativa (Runciman, 1966) e a hipótese frustração-agressão (Berkowitz, 1972) comporiam a explicação sobre o engajamento dos indivíduos em movimentos sociais. Klandermans (1997), baseado em tais teorias, propõe que a participação em protestos estaria vinculada a um sentimento de injustiça composto por uma percepção de desigualdade ilegítima, queixas repentinamente impostas e indignação moral.

As queixas são sem dúvidas essenciais para o processo de mobilização, no entanto, elas por si só não são o bastante. Por exemplo, segundo dados ${ }^{3}$ de 2018, o déficit habitacional na cidade de São Paulo seria de 358 mil moradias, mas apenas uma parte ínfima das pessoas afetadas por este déficit se mobiliza em movimentos de luta pelo direito a habitação.

A partir do final dos anos 1960, surgem novas propostas de entendimento de movimentos sociais. A luta por direitos civis nos EUA e as grandes manifestações na Europa levaram acadêmicos a reavaliarem seus modelos. Emerge neste contexto a chamada

\footnotetext{
${ }^{1}$ No original: "toute occupation momentanée par plusieurs de personnes d'un lieu ouvert, public ou privé et qui comporte directement ou indirectement l'expression d'opinions politiques”.

${ }^{2}$ Societal breakdown theories.

${ }^{3}$ Dados da Secretaria Municipal de Habitação de São Paulo.
} 
teoria da mobilização de recursos (TMR). Segundo a TMR (McCarthy \& Zald, 1973; Olson, 1965), não bastam pessoas queixosas para a formação de um movimento social, pois também seriam necessários recursos humanos e materiais - para tal. Nesta proposta, os indivíduos não seriam levados à participação por pulsões irracionais ou pela mera manipulação de uma liderança. Ao contrário, o engajamento em um movimento social se daria pela racionalidade instrumental baseada em cálculos de custos e benefícios. Retomando o exemplo do déficit habitacional, a TMR diria que não basta existir a queixa ou problema, é necessário que os indivíduos sintam que há recursos suficientes para que haja êxito no movimento. Neste caso, as pessoas precisam confiar na organização de luta por moradia, assim como em seus repertórios de ação e em sua eficácia (Rodrigues, 2002). Os indivíduos avaliariam os elementos favoráveis e contrários a sua participação e, a partir de um cálculo racional, decidiriam participar ou não do movimento. A TMR nega a irracionalidade com que as ações coletivas eram predominantemente entendidas até então e propõe um modelo racionalista. Para essa abordagem, abolir a concepção de irracionalidade vinculada aos movimentos significava abolir as emoções de seu modelo teórico.

A psicologia social estava, até então, relacionada fortemente às teorias da queixa. Assim, a crise dessas teorias acarretou também a crise entre as referências psicossociais que se propunham a entender os movimentos sociais. Klandermans (1984) propõe uma expansão psicossocial da teoria da mobilização de recursos, que visava explicar a razão de certas pessoas lesadas participarem em protestos enquanto outras, também lesadas, optam por não participar. O centro da expansão psicossocial da TMR funda-se na "expectativa do indivíduo de que determinados resultados irão se materializar, multiplicada pelo valor daqueles resultados para o indivíduo" ${ }^{4}$ (Van Stekelenburg \& Klandermans, 2017, p. 107, tradução nossa). Como é evidente, a proposta se baseia na premissa de que, para entender os comportamentos dos indivíduos, mais do que apenas o ambiente objetivo, faz-se necessário avaliar suas percepções e interpretações de dado contexto. Os recursos são necessários, mas a decisão racional de aderir ou não ao movimento passa pela percepção e interpretação de tais recursos pelos indivíduos.

A adoção da perspectiva racionalista cria um dos grandes dilemas relacionados à participação em movimentos sociais, o dilema dos caronistas. Vários movimentos sociais têm reivindicações que vão além de seus participantes diretos. Assim, muitas pessoas podem se beneficiar dos ganhos do movimento sem sequer ter dele participado ou mesmo o apoiado. Essas pessoas são os caronistas. Como explicar, a partir de uma perspectiva racionalista instrumental, que determinadas pessoas se neguem a "pegar carona" no movimento e, ao contrário, se dediquem à militância e até mesmo coloquem suas vidas em risco em algumas situações?

Na tentativa de evitar caronistas, algumas organizações condicionam os possíveis ganhos dos movimentos sociais a uma participação mínima dos indivíduos. É comum no Movimento dos Trabalhadores Sem Teto (MTST) o condicionamento da conquista do lar à participação em atividades e presença nos acampamentos (Rodrigues, 2002). No entanto, o dilema persiste, pois nem todos os movimentos podem se organizar dessa forma. Por exemplo, a luta contra o reajuste do valor das passagens de ônibus em 2015, que resultou nas Jornadas de Junho, fez com que houvesse um recuo no preço do transporte coletivo para todas e todos - participantes ou não dos protestos. Ainda sabendo que a vitória se estenderia a participantes ou não das jornadas, muitas pessoas se propuseram a estar nas ruas oferecendo seu tempo, energia e colocando-se, em alguns momentos, em risco físico.

Também negando o caráter irracional anteriormente proposto nos estudos dos movimentos sociais, a teoria do processo político (TPP) foca em elementos macrossociais que compõem as oportunidades políticas em determinado momento histórico (McAdam, 1982). Além das queixas e dos recursos disponíveis, também são evidenciadas como relevantes as oportunidades políticas existentes em um contexto específico ${ }^{5}$. No cenário brasileiro, Boschi (1987) se propõe a analisar as manifestações ocorridas entre o final da década de 1970 e meados da década de 1980. O entendimento desses movimentos passa pela compreensão do contexto político brasileiro mais amplo, vinculado ao período de redemocratização

\footnotetext{
${ }^{4}$ No original: “. . . the individual's expectation that specific outcomes will materialize, multiplied by the value of those outcomes for the individual".

${ }^{5}$ Tilly (1978) distingue sistemas políticos em termos de "repressão" e "facilitação". O autor se refere, respectivamente, a sistemas que diminuem ou aumentam o custo da participação política.
} 
do país. As oportunidades políticas proporcionadas por determinada conjuntura histórica tornam-se cruciais no entendimento da mobilização política.

Diante das elaborações advindas da TMR e da TPP, a psicologia social propõe utilizar o conceito de eficácia para entender a decisão dos indivíduos em participar ou não de um movimento social. A eficácia diz respeito às expectativas dos indivíduos relacionadas à possibilidade de a ação coletiva de fato gerar alguma mudança nas condições e políticas vigentes (Gamson, 1992). Quanto mais um indivíduo acredita que determinado protesto será eficaz, maiores as chances de ele participar. Essa eficácia é composta essencialmente pela percepção dos recursos e oportunidades presentes em determinado contexto. Sandoval (2001) mostra como o contexto de neoliberalização e globalização, a partir dos anos 1990, afetou a eficácia política de muitos trabalhadores brasileiros. Segundo o autor, ao atribuir as causas das queixas a entidades transcendentais (ondas internacionais de neoliberalismo e globalização), o sentimento de eficácia é reduzido abruptamente, pois a possibilidade de afetar tais entidades é quase inexistente. Diante de tal cenário, a propensão a participar de uma greve cai de forma significativa, como demonstra sua pesquisa.

Uma quarta abordagem nos estudos dos movimentos sociais ainda merece destaque. A teoria dos novos movimentos sociais (TNMS) não constitui uma escola coesa, mas pode ser classificada de forma ampla como uma abordagem que propõe uma interpretação de fato cultural para os movimentos (Alonso, 2009). Diferentes referenciais da TNMS (Eyerman \& Jamison, 1991; Morris \& Mueller, 1992; Laraña, Johnson, \& Gusfield, 1994), mesmo que de forma diversa, colocam como centrais a construção de sentidos, formação de identidade e a cultura. A TNMS foi, entre as teorias abordadas até então, a que mais se propagou na América Latina até o início do século XXI (Alonso, 2009). No Brasil, podemos destacar a obra Quando novos personagens entraram em cena de Eder Sader. Sob influência de Touraine, Sader (1988) analisa movimentos sociais de São Paulo entre 1970 e 1980 e demonstra como tais movimentos trazem à luz novos sujeitos políticos fundamentais para o processo de redemocratização do país.
No que se refere ao campo da psicologia social, a TNMS faz emergir um elemento central à discussão psicossocial, a identidade. A partir dos anos 1980, a instrumentalidade expressa nas queixas, recursos e oportunidades mostrava-se ainda insuficiente para o entendimento do engajamento político. A ideia de identidade coletiva, então, surge como elemento fundamental para o processo de participação em movimentos sociais e protestos. Importante ressaltar que as abordagens aqui apresentadas, mais do que concorrentes entre si, devem ser entendidas como complementares. Segundo Klandermans (1997, p. 205, tradução nossa, grifos do autor original):

Obviamente, queixas não são razões suficientes para movimentos sociais se desenvolverem, ou para indivíduos participarem em movimentos sociais. Certamente, recursos e oportunidades são importantes para entender porque certas populações lesadas se mobilizam e outras não. E, com certeza, indivíduos geram uma identidade comum quando eles dividem queixas e agem coletivamente. Mas isso não justifica nenhum direito exclusivo de domínio ${ }^{6}$.

\section{Motivos para participação}

Segundo Van Stekelenburg e Klandermans (2017, p. 122), "motivação é o desejo de atingir um objetivo combinado com a energia para trabalhar em direção a tal objetivo"'. A psicologia social do protesto tem como uma de suas grandes metas a busca dos motivos que levam as pessoas a se engajarem em uma ação coletiva. O primeiro motivo central proposto pelos psicólogos sociais do protesto foi a instrumentalidade. As pessoas participariam ou não de movimentos sociais baseados em um cálculo de custo e benefício; este cálculo teria como componentes principalmente a percepção sobre os recursos dos movimentos e as oportunidades políticas presentes em certo contexto. Diante da percepção dos recursos e oportunidades, emergiria (ou não) o sentimento de eficácia dos indivíduos em relação a suprir determinada queixa.

\footnotetext{
${ }^{6}$ No original: "Obviously, grievances are not sufficient reasons for social movements to develop, or for individuals to participate in social movements. Certainly, resources and opportunities are important to understand why some aggrieved populations do mobilize and others don't. And indeed, individuals do generate a common identity when they come to share grievances and act collectively. But this doesn't justify any exclusive right to the domain".

${ }^{7}$ No original: "Motivation is the desire to achieve a goal, combined with the energy to work towards that goal".
} 
No entanto, com o tempo, a instrumentalidade passa a mostrar-se insuficiente para o entendimento da participação em protestos.

Retomamos aqui o já citado dilema do caronista. A partir de abordagens instrumentais o dilema torna-se de difícil solução. Olson (1965) propõe que incentivos seletivos poderiam ajudar a tornar o cálculo de custo e benefícios favorável à participação. Diferentes dos incentivos coletivos, que se relacionam a ganhos de bens públicos, os incentivos seletivos estão vinculados a meios de ação atrativos para os sujeitos. Por exemplo, o incentivo coletivo ligado à luta pelo direito à diversidade sexual e de gênero pode ser mais ou menos atrativo, mas dificilmente é capaz, por si só, de mobilizar centenas de milhares de pessoas em um evento. No entanto, quando tal incentivo coletivo é combinado com incentivos seletivos como shows e trios elétricos - como é o caso da parada LGBT de São Paulo - o movimento é capaz de conseguir a adesão de centenas de milhares de pessoas ${ }^{8}$ (Silva, 2008).

Mesmo com a adoção do conceito de incentivos seletivos, o dilema do caronista mostra-se de difícil solução pelos modelos racionalistas e instrumentais. O caso da militante sem-terra Maria ilustra tal dificuldade (Rosa, 2017). Maria estava grávida e morava com seus outros oito filhos em um acampamento vinculado ao Movimento dos Trabalhadores Rurais Sem Terra (MST) no interior paulista. Os moradores deste acampamento foram despejados de seus barracos pela polícia, que cumpria uma ordem de reintegração de posse. Os ex-acampados não tinham para onde ir; foram levados para um colégio onde ficariam temporariamente. Maria havia tido seu nono filho pouco tempo antes da reintegração de posse. Suas companheiras e companheiros disseram para que ela fosse com seus filhos passar um tempo com alguns parentes. Segundo eles, ela deveria descansar e cuidar do recém-nascido. Os membros do MST asseguraram que Maria teria garantido seu direito a um lote mesmo ficando afastada do movimento por algum tempo. Ou seja, Maria poderia optar por uma situação de evidente maior conforto e segurança para sua família sem ter prejuízo algum; seria uma situação típica de carona. No entanto, Maria optou por permanecer com os companheiros do movimento mesmo naquelas condições extremas. Em seu relato, ela diz que não poderia deixar aquelas pessoas, pois havia sido acolhida por elas desde a sua chegada ao acampamento. Maria diz que era capaz de sentir o amor de seus companheiros de movimento. Ela define o movimento como sua família ${ }^{9} \mathrm{e}$ diz que não a abandonaria. A instrumentalidade relacionada à conquista da terra, certamente compõe a motivação de Maria para participar do movimento social, no entanto, este motivo não explica de forma suficiente seu engajamento.

O caso de Maria nos ajuda a perceber as dificuldades encontradas pelas abordagens exclusivamente instrumentalistas. A proposta de Olson (1965) mostra-se muito pertinente para explicar porque as pessoas não participariam de mobilizações, mas pouco eficaz para explicar a participação. Nos relatos de Maria evidencia-se a importância dos vínculos e da solidariedade existentes entre ela e outros membros da organização. Uma das grandes críticas feitas a Olson é a forma como seu modelo toma os indivíduos como seres que decidem e agem isoladamente. Como o exemplo de Maria evidencia, as pessoas constroem vínculos com as outras, agem e decidem dentro de determinadas redes sociais. Gradativamente um novo motivo passa a ser entendido como fundamental para o engajamento em movimentos sociais: a identidade coletiva.

Muitos movimentos levam anos para conseguir suas reivindicações, isto quando as alcançam. Apenas avaliações de custos e benefícios não poderiam explicar o engajamento em movimentos sociais de forma adequada. Neste contexto surge, como uma forte proposta para compor tal explicação, a identidade coletiva, entendida como um motivo que fundamenta todo o processo de engajamento em protestos. Polletta e Jaspers (2001, p. 285) definem identidade coletiva como

... uma conexão cognitiva, moral e emocional de um indivíduo com uma comunidade mais ampla, categoria, prática ou instituição. É a percepção de uma condição ou relação partilhadas, a qual pode ser imaginada mais que experienciada direta-

\footnotetext{
${ }^{8}$ Segundo organizadores da parada LGBT de São Paulo, o evento contou com a participação de 3 milhões de pessoas em 2018.

${ }^{9}$ A identificação do movimento como família está presente em outros trabalhos. Consultar Tristan (1987) e Orfali (1990).
} 
mente, e é distinta das identidades pessoais, ainda que possa fazer parte de uma identidade pessoal ${ }^{10}$.

No entanto, apenas a existência de uma identidade coletiva não acarreta inevitavelmente a participação em uma ação coletiva. É necessário que tal identidade seja politizada. Três elementos diferem uma identidade coletiva politizada de uma não politizada (van Stekelenburg \& Klandermans, 2017). Primeiramente, a identidade coletiva politizada implica em um maior nível de consciência, ou seja, implica que os membros do grupo tenham uma maior compreensão do mundo social ao seu redor e do lugar ocupado por eles neste mundo. Em segundo lugar, identidades coletivas politizadas proporcionam uma visão antagonista para a interpretação das relações sociais. Isto é, outros grupos sociais são classificados como aliados ou adversários nas diferentes arenas políticas. O terceiro elemento diz respeito às consequências comportamentais da identidade coletiva politizada. Indivíduos com identidades mais politizadas teriam maior probabilidade de participar em ações coletivas politicamente orientadas.

Em resumo, a ideia básica relacionada à identidade coletiva e ao engajamento em movimentos sociais é bastante simples: quanto maior a identificação com determinado grupo, mais provável será a participação em ações políticas de tal grupo.Várias evidências empíricas corroboram com tal hipótese (Kelly \& Breinlinger, 1996; Simon et al., 1998; Klandermans, Sabucedo, \& Rodriguez, 2002). No Brasil, pesquisas têm abordado o conceito de identidade coletiva em diferentes áreas. Camino et al. (1995) e Camino et al. (1998) demonstram, em pesquisa realizada nos anos 1990, que a identificação partidária ainda desempenhava um papel relevante no comportamento eleitoral dos brasileiros. A partir de uma perspectiva ético-estética, Maheirie (2002) defende a importância da música popular brasileira como linguagem política capaz de mediar a construção de identidades coletivas. Sandoval (2001) demonstra como a fragmentação da identidade coletiva entre trabalhadores brasileiros nos anos 1990 coloca-se como um fator relevante de desmobilização do setor.

Desde a superação das teorias do colapso social, as emoções foram, por algum tempo, negligenciadas nos estudos dos movimentos sociais. Na tentativa de superar a concepção de movimentos sociais como ações coletivas irracionais, os teóricos da TMR e TPP acabaram negligenciando o papel desenvolvido pelas emoções no processo de participação política. Seja por meio do modelo racionalista ou do modelo estruturalistas, as duas escolas praticamente baniram as emoções de suas propostas (Jasper, 2011). Por sua vez, a TNMS deu novo espaço às emoções e à expressividade. Aos poucos, emoções e racionalidade deixam de ser entendidas como elementos contrastantes e dicotômicos. Surge, então, o terceiro motivo presente no modelo de participação da psicologia social do protesto: a expressividade e emoção.

Muitos estudos empíricos têm destacado a raiva como uma emoção fundamental para o processo de participação em protestos (Jasper, 2011; Van Stekelenburg \& Klandermans, 2010; Van Troost, Van Stekelenburg, \& Klandermans, 2013). Importante destacar que a raiva à qual nos referimos é uma raiva predominantemente baseada no grupo, ou seja, uma raiva que não está relacionada apenas ao indivíduo, mas a grupos com os quais ele se identifica. A raiva leva as pessoas a terem posições mais desafiadoras diante de grupos opositores em comparação a emoções subordinadas como vergonha, desespero e medo. A raiva motiva as pessoas a lutarem contra os agentes entendidos como responsáveis pelas queixas do grupo, ela conduz as pessoas a agir por justiça, retribuição ou vingança. Van Troost et al. (2013) destacam duas rotas emocionais de protesto. A primeira é a "rota da raiva", que está vinculada ao sentimento de eficácia dos sujeitos e conduz a demonstrações públicas lícitas. Por sua vez, a segunda é a "rota do desprezo", que leva a posições de "nada a perder" e, consequentemente, a repertórios mais violentos de ação. Essa segunda rota se manifesta geralmente quando os canais legítimos de protesto estão fechados e a situação é percebida como sem esperanças.

As pessoas são motivadas a participar em movimentos sociais e protestos, pois pretendem mudar determinadas situações (instrumentalidade); pois querem atuar como membros de certos grupos (identidade); mas também para expressar suas visões de mundo e emoções. No contexto brasileiro, podemos tomar como exemplo as manifestações surgidas a partir do assassinato da vereadora e militante dos direitos humanos Marielle Franco ${ }^{11}$. No dia 14 demarço de2018,

\footnotetext{
${ }^{10}$ No original: “. . an individual's cognitive, moral, and emotional connection with a broader community, category, practice, or institution. It is a perception of a shared status or relation, which may be imagined rather than experienced directly, and it is distinct from personal identities, although it may form part of a personal identity"

${ }^{11}$ Para mais informações consultar o endereço eletrônico https://www.mariellefranco.com.br/.
} 
Marielle e seu motorista Anderson Pedro Gomes foram assassinados. As investigações têm relacionado o crime a milícias da cidade do Rio de Janeiro (Betim, 2021). Após o assassinado, várias manifestações se espalharam pelo país. Segundo o partido da vereadora (Partido Socialismo e Liberdade [Psol], 2018), no dia seguinte ao assassinato (15/03/2018) havia atos marcados em doze cidades por todo o país. Essas manifestações se dão por motivos instrumentais: as pessoas querem que o crime seja devidamente investigado e que os envolvidos sejam punidos. Os atos também ocorrem por razões identitárias: muitas pessoas - mulheres, negras, pobres, lésbicas, progressistas, militantes de direitos humanos, militantes do mesmo partido que a vereadora etc. - se identificam como membros dos grupos que estão encampando as ações e querem agir como parte deles. No entanto, a participação nas manifestações também se fundamenta em forte sentimento de indignação moral despertado pelo covarde assassinato da militante. Muitos dos participantes tinham grandes dúvidas quanto à resolução do caso e muitos não faziam parte do partido de Marielle ou de seus grupos, mas ainda assim essas pessoas foram às ruas expressar sua raiva e indignação diante do crime.

As vias propostas para a participação política em movimentos sociais - instrumentalidade, identidade, expressividade e emoções - não devem ser entendidas como modelos em disputa, mas trabalhadas em conjunto. Esses motivos compõem a motivação de grande parte dos participantes em movimentos e protestos. Em síntese, a instrumentalidade diz respeito à tentativa de influenciar o ambiente político e social no qual o sujeito se insere. A identidade se refere à identificação do sujeito com um grupo como o motor da participação em movimentos. E, por fim, a expressividade e as emoções estão relacionadas ao desejo dos sujeitos de expressar suas visões de mundo e liberar sua raiva e indignação contra alvos que os tenham atacado material ou simbolicamente.

A Figura 1 apresenta um esquema que sintetiza a dinâmica dos motivos de participação em protestos.

\section{Figura 1}

Modelo integrativo de motivação para participação em protestos.

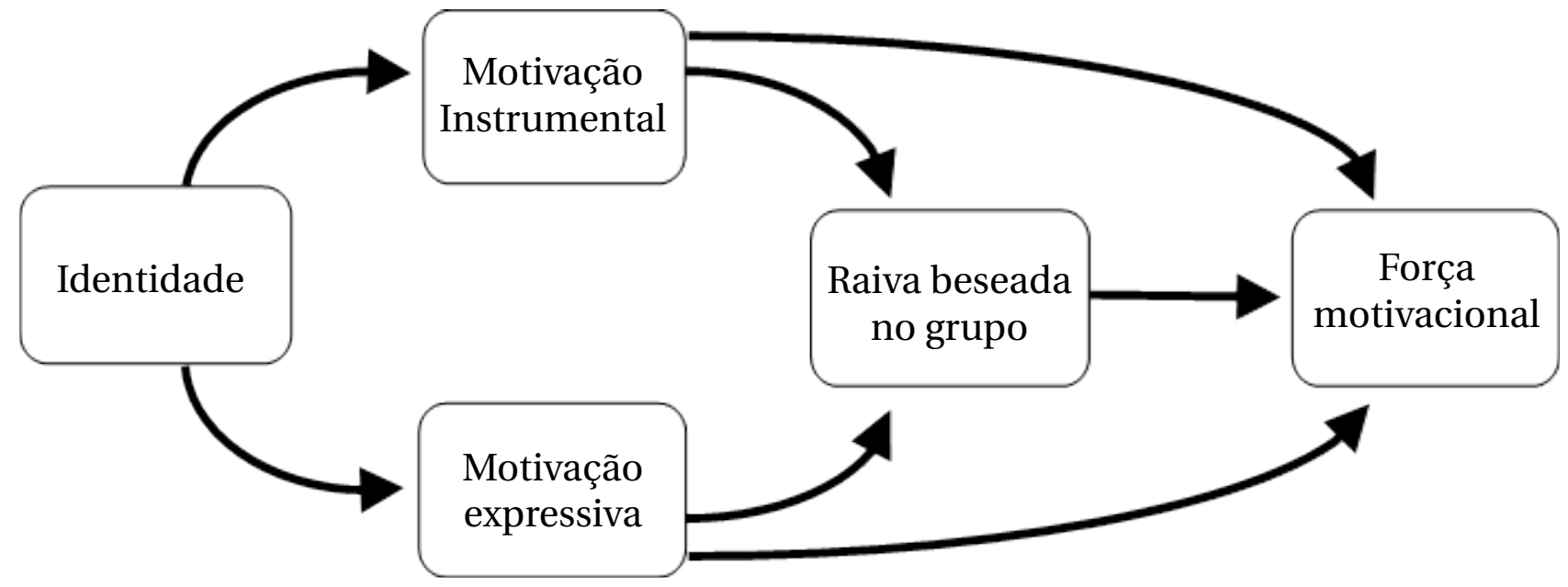

Fonte: van Stekelenburg e Klandermans (2017, tradução nossa).

\section{Demanda, oferta e mobilização}

O processo de participação em um movimento social não envolve apenas a análise da dimensão vinculada aos indivíduos que podem ou não se engajar. Elementos como a organização dos movimentos e as oportunidades políticas presentes no contexto são indispensáveis para a compreensão do processo. Na tentativa de produzir um modelo que aborde a dinâmica dessas diferentes dimensões, adotamos a metáfora da "oferta e demanda" (Klandermans, 1997, 2015).

A demanda diz respeito ao potencial que determinado contexto social tem para o engajamento em um protesto específico. A oferta, por sua vez, refere-se às oportunidades oferecidas por organizações e grupos para que tal protesto ocorra. A ligação entre 
a demanda e a oferta, que produz o protesto efetivamente, se dá por meio do processo de mobilização. Continuando na metáfora econômica, poderíamos entender a mobilização como o mecanismo de "marketing" dos movimentos sociais, ou seja, é ela que vincula os potenciais (demanda) e as oportunidades (oferta) de participação. Em síntese,

Dentro desse quadro, a participação em um movimento social é o resultado de um processo de mobilização que traz a demanda por protestos políticos existente em uma sociedade ao encontro de uma oferta de oportunidades para se tomar parte em protestos oferecida por movimentos sociais organizados (Klandermans, 2015, p. 126).

Os motivos trabalhados no tópico anterior devem ser abordados a partir de cada um dos lados da dinâmica exposta, ou seja, devemos entender como os motivos - instrumentalidade, identidade e expressividade e emoções - compõem a oferta e a demanda da participação em protestos.

Primeiramente, abordemos o elemento que liga o lado da oferta e o lado da demanda, ou seja, a mobilização. O processo de mobilização deve ser dividido em mobilização-consenso e mobilizaçãoação. A mobilização-consenso refere-se à propagação dasideias e posições defendidas por determinado movimento. No momento da mobilização-consenso, as pessoas são convencidas de que as causas que levam à ação coletiva são justas e os meios utilizados legítimos, ou seja, a mobilização-consenso visa produzir simpatizantes. No entanto, tal convencimento ou simpatia não são bastantes para garantir a participação em uma ação coletiva. Na tentativa de garantir a participação dos sujeitos já simpatizantes ao movimento, se dá a mobilização-ação (Klandermans \& Oegema, 1987).

Podemos ilustrar o processo de mobilização por meio das ocupações estudantis paulistas de 2015, movimento que resultou na ocupação de mais de 200 escolas públicas de ensino fundamental e médio no estado de São Paulo ${ }^{12}$ (Campos, Medeiros, \& Ribeiro, 2016). Segundo uma pesquisa do Instituto Datafolha de 2016, a tática de ocupação de escolas em defesa da educação pública foi apoiada por cerca de $60 \%$ dos estudantes paulistanos, ou seja, mais da metade dos estudantes colocaram-se a favor dos atos (Saldaña \& Lazzeri, 2016). Aparentemente a mobilização-consenso havia sido bem-sucedida entre os estudantes, isto é, havia um grande número de simpatizantes ao movimento. No entanto, apenas aproximadamente $6 \%$ dos alunos e alunas participou efetivamente das ações. O número de pessoas simpatizantes normalmente é muito maior do que o de pessoas que participam de fato das ações coletivas, pois os simpatizantes não se convertem instantaneamente em militantes ou participantes; para isso, faz-se necessária a mobilização-ação.

A primeira questão dentro do processo de mobilização-ação se refere a quais simpatizantes serão contatados para participar de determinada ação ou quais serão atingidos pelas tentativas de mobilização de um movimento. Dada a necessidade de sigilo sobre as ações de ocupações escolares de 2015, muitos dos estudantes sequer ficavam sabendo sobre os atos antes que eles ocorressem. Assim, uma parte significativa de potenciais apoiadores foi impossibilitada de participar simplesmente por não ser informada sobre as ocupações. Ademais, dentre os informados, nem todos se motivaram a participar. Mesmo sendo simpáticos à causa, muitos estudantes, por exemplo, temiam fortes repressões, sejam elas das gestões escolares sejam da polícia. Após as ocupações ocorrerem, presumimos que praticamente todos os estudantes estavam informados sobre o ato, no entanto, ainda assim apenas uma parte mostrou-se motivada a participar. Por fim, mesmo dentre aqueles simpatizantes, informados e motivados, alguns não efetivaram sua participação, pois foram impedidos por alguma barreira. Por exemplo, uma razão da não participação muito presente nos relatos dos estudantes é a proibição dos pais. Assim, muitos apoiadores informados e motivados não puderam ocupar suas escolas. Percebe-se que o processo de mobilização implica uma diminuição gradativa da quantidade de pessoas a cada etapa. A Figura 2 sintetiza as fases descritas acima.

\footnotetext{
${ }^{12}$ Os estudantes reivindicavam o direito de serem ouvidos sobre a proposta de "reorganização" do ensino promovida pelo governo estadual. A proposta do governo reorganizaria os ciclos de ensino das escolas estaduais e previa o fechamento de 92 escolas, afetando diretamente cerca 311 mil estudantes e 74 mil professores.
} 
Figura 2

Processo de mobilização-ação.

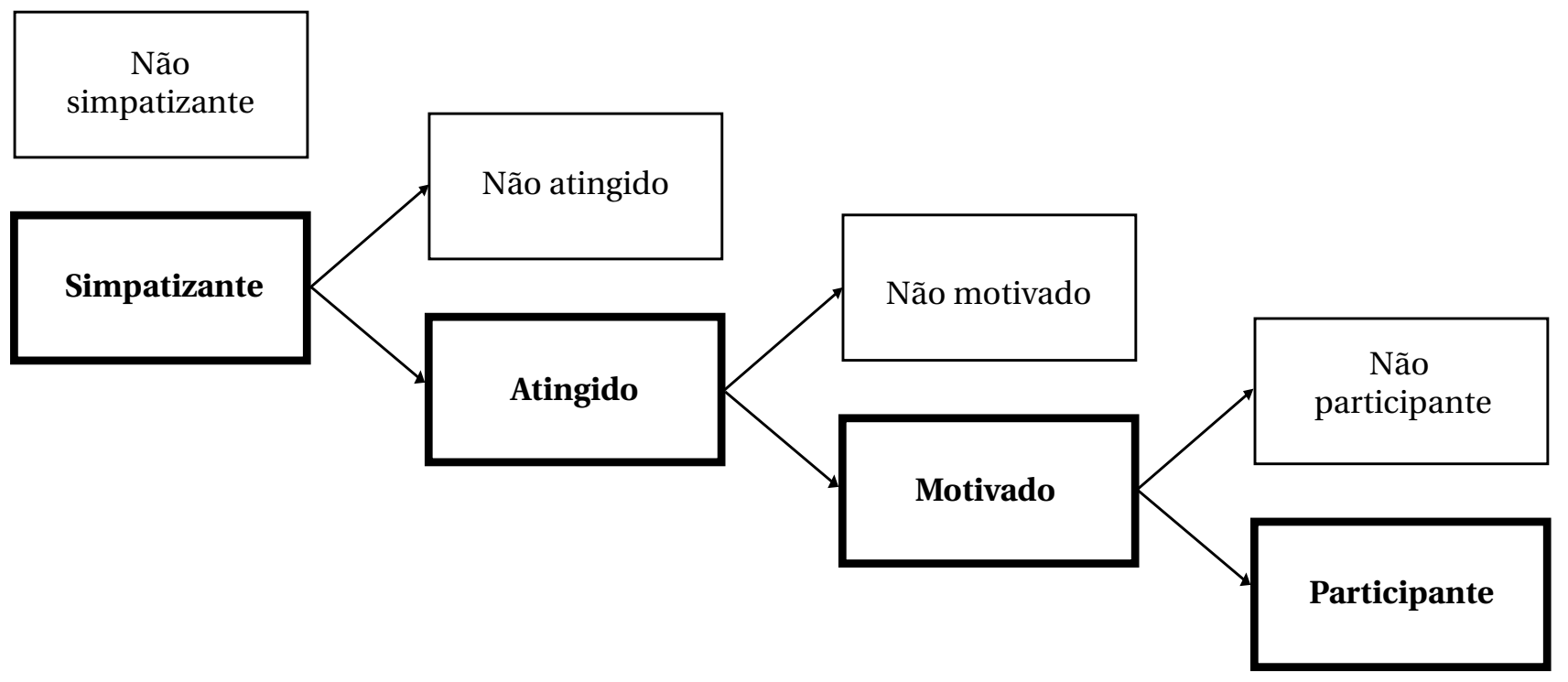

Fonte: Klandermans \& Oegema (1987, tradução nossa).

A cada um dos passos demonstrados na Figura 2, a demanda e a oferta de participação se aproximam e, por fim, se encontram na participação concreta na ação coletiva. Dentre os momentos expressos da figura, o primeiro e o terceiro são os mais interessantes psicossocialmente. O processo de tornar um membro da população geral um simpatizante do movimento e a tentativa de motivar simpatizantes para participar de uma ação coletiva são questões diretamente relacionadas à psicologia social. Ao abordar tais questões em especial a segunda-retomamos a discussão sobre os motivos da participação em movimentos sociais e protestos. Discorreremos a seguir sobre cada um dos motivos atrelados a cada dimensão de oferta ou demanda.

No que diz respeito à instrumentalidade, o lado da demanda refere-se às queixas de determinados indivíduos sobre sua atual situação. As pessoas "demandam" a solução de algum problema ou a mudança de determinada situação que não as agrada. No entanto, como já vimos, as queixas por si só não são o suficiente para que os indivíduos se engajem em determinada ação coletiva. Muitas pessoas têm queixas, mas muito poucas participam de movimentos sociais. Para que a instrumentalidade se efetive como motivo, é preciso que as pessoas desenvolvam uma percepção de eficácia relacionada ao protesto, que é composta principalmente pela percepção dos recursos do movimento e das oportunidades políticas do contexto.
É exatamente a esses elementos que a oferta se relaciona quando aborda a instrumentalidade. As organizações de movimentos sociais precisam "ofertar" não só a luta em prol da resolução de certa queixa, mas também a percepção de eficácia sobre tal luta, ou seja, precisam demonstrar que o movimento possui recursos suficientes e que há oportunidades políticas favoráveis. Outro fator importante relacionado à instrumentalidade ofertado pelas organizações são os já citados incentivos seletivos, que buscam tornar o cálculo de custo e benefício mais favorável à participação.

Ilustraremos a relação entre oferta e demanda a partir da instrumentalidade utilizando-se da popularidade do governo de Michel Temer (2016-2018). Segundo pesquisa realizada pelo Instituto Datafolha em junho de 2018, a gestão Temer era reprovada por $82 \%$ dos brasileiros - a maior reprovação de um presidente já registrada (Instituto de Pesquisas Datafolha, 2018). A taxa de reprovação demonstrava queixa generalizada contra o presidente, de modo que os índices eram piores que os relativos à presidenta Dilma Rousseff, que teve seu impeachment apoiado por grandes manifestações de rua. No entanto, as manifestações contrárias à gestão Temer não se massificaram. Por diversas razões e a partir de diversas posições políticas, havia demanda por mudanças no governo Temer, porém, os protestos, de maneira geral, não lograram tão grande número de adeptos. Evidencia-se novamente que queixas por 
si só não são o bastante para o engajamento político, ou seja, mesmo queixosas, as pessoas não foram convencidas de que as ações possuiriam suficientes recursos e que as oportunidades políticas seriam suficientemente favoráveis. Uma análise com foco apenas na instrumentalidade poderia avaliar que as organizações contrárias a Temer falharam em ofertar uma percepção de eficácia que poderia produzir maiores mobilizações. Importante pontuar que, para fins de ilustração, isolamos a motivação instrumental no exemplo acima, porém, a real análise psicossocial deve ser feita a partir da interação dos diversos motivos. Além disso, ao abordar tal caso, não pretendemos analisá-lo em sua complexidade, mas apenas potencializar o entendimento da dimensão instrumental da participação política a partir desse exemplo.

A identidade, entendida a partir do lado da demanda, diz respeito à motivação de determinados indivíduos para agirem como membros de grupos específicos. As pessoas compartilham identidades coletivas - vínculos afetivos, comprometimentos, objetivos comuns, sentimentos de solidariedade e se sentem motivadas a agirem em consonância com seus pares. Como já abordado, os indivíduos "demandam" ações que fortaleçam e evidenciem suas identidades coletivas (Klandermans \& de Weerd, 2000). Do lado da oferta, as organizações de movimentos sociais buscam suprir as necessidades identitárias das pessoas. No processo de mobilização, as organizações pretendem "ofertar" elementos identitários para suprir necessidades já existentes, mas também com o intuito de constituir novas identidades coletivas. Músicas, vestimentas, símbolos, palavras de ordem e repertórios de ação são exemplos de elementos identitários que podem compor os movimentos sociais (Tilly, 2004).

Utilizando-se do exemplo do MST, podemos destacar um importante mecanismo de produção de laços sociais, a mística. Lara Junior $(2007,2010)$ discute como a mística se constitui a partir de elementos políticos e religiosos e ocupa um importante papel dentro da dinâmica do MST. A mística no MST configura-se como momentos de práticas celebrativas que podem ser compostos por depoimentos, músicas, encenações, danças, rituais, rezas, símbolos e palavras de ordem relacionados às pautas do movimento. Segundo Lara Junior e Prado (2004), a mística é um componente fundamental no processo de constituição da identidade coletiva entre os membros do MST. Tal prática delimita as fronteiras entre um "nós" e um "eles", circunscrevendo aliados e adversários e politizando as identidades.

O lado da demanda relacionado ao terceiro motivo de engajamento em protestos se refere ao desejo dos indivíduos em expressar determinada visão de mundo ou emoções vinculadas a um assunto ou situação específicos. As organizações de movimentos sociais tendem a produzir mecanismos para suprir a demanda de expressividade de seus membros e simpatizantes. Por meio de sua organização e repertórios de ação, os movimentos visam canalizar as motivações emocionais e expressivas; esses repertórios devem ser planejados de forma a dar vazão a tal demanda.

Por exemplo, em junho de 2013, durante um acampamento em frente à prefeitura da cidade de Ribeirão Preto (SP) ${ }^{13}$, um grupo de mulheres, que formava uma cooperativa de trabalho com lixo reciclável, falou diante dos acampados e pediu o apoio do movimento em prol de sua causa ${ }^{14}$. Após o fim da assembleia, uma das cooperadas disse estar se sentindo muito bem, pois nunca tivera um espaço como aquele em que pudesse falar de sua situação. Mesmo sem nenhum ganho concreto, o simples fato de ela ter expressado e compartilhado seus ideais e emoções, o fato de ter sido ouvida, fez com que ela se motivasse em apoiar o movimento. O acampamento, mesmo que de forma não totalmente intencional, produziu uma oferta para suprir a demanda daquela mulher de se expressar. A mística do MST cumpre também esse papel de "oferta expressiva e emocional". Além de criar laços identitários, as pessoas compartilham visões de mundo e sentimentos durante as místicas (Lara Junior, 2007).

Finalizamos o presente tópico ressaltando a importância de entender os motivos e dimensões propostos de forma articulada. Instrumentalidade, identidade e expressividade e emoções não podem ser tomados como isolados uns dos outros. Eles devem ser compreendidos em seu conjunto e em suas influências mútuas.

\footnotetext{
${ }^{13}$ Um dos autores estava presente durante a manifestação. As principais pautas do acampamento eram a diminuição da tarifa de transporte pública da cidade e a criação de um conselho municipal de transporte coletivo. Para informações da impressa: http://g1.globo.com/ sp/ribeirao-preto-franca/noticia/2013/07/apos-12-dias-acampados-deixam-praca-da-prefeitura-de-ribeirao-preto.html.

${ }^{14}$ As trabalhadoras reivindicavam melhores acordos de cooperação junto à prefeitura de Ribeirão Preto (SP).
} 


\section{Considerações finais}

A psicologia social do protesto propõe-se a abordar a participação política em ações coletivas tendo como unidade de análise o indivíduo e seu comportamento social. Esse enquadramento teórico e metodológico possibilita trabalhar sobre as motivações que levam uma pessoa a participar ou não de um protesto e, até mesmo, contribui para o entendimento do processo de desengajamento de militantes de um determinado movimento social (Klandermans, 2015). No entanto, o nível de análise e o individualismo metodológico adotados detêm os principais limites da abordagem. Teorias da psicologia social flertam muitas vezes com uma pretensão de universalidade, o que acarreta também um risco de a-historicismo. Faz-se necessário compreender os indivíduos dentro de seus contextos sócio-históricos e entender que processos cognitivos têm relações - e muitas vezes raízes - em processos sociais (Lane \& Codo, 2004). Além disso, seria pertinente o desenvolvimento de abordagens menos estáticas e mais dinâmicas para explicar a participação nos movimentos sociais. Um olhar com maior foco nos processos e em suas dinâmicas pode produzir significativos avanços nos estudos sobre participação política a partir da psicologia social.

O referencial apresentado é uma abordagem desenvolvida, conhecida e aplicada predominantemente nos EUA e na Europa. Defendemos que, a partir de décadas de elaborações teóricas e empíricas, a psicologia social do protesto tem muito a contribuir para o entendimento de protestos e movimentos sociais também no Brasil e na América Latina. No entanto, entendemos que tais contribuições devem ser feitas em profundo diálogo com os referenciais brasileiros e latino-americanos. Não se trata de uma adoção mecânica e acrítica de um referencial, tampouco de ignorar uma produção pelo simples fato de ela ser produzida em um contexto diverso. O desafio que se apresenta é constituir um potente campo de diálogo em que os limites e possibilidades das diferentes escolas possam ser confrontados. Assim, indica-se que sejam desenvolvidas futuras pesquisas que abordem - não apenas de forma panorâmica e ilustrativa, mas com a profundidade necessária-as potências e insuficiências da psicologia social do protesto na análise de fenômenos políticos brasileiros específicos.

Enfim, em consonância com a tradição latino-americana crítica em psicologia social e política, pretendemos que as discussões que possam emergir do presente trabalho contribuam para o desenvolvimento de instrumentos conceituais úteis a acadêmicos e movimentos sociais democráticos. Entender mecanismos que constituem o engajamento de indivíduos em movimentos sociais e protestos se faz pertinente também para atuações críticas e comprometidas de profissionais da psicologia. Tais profissionais podem contribuir diretamente junto a movimentos sociais e ações coletivas, assim como compor processos de mobilização a partir de atuações, principalmente em políticas públicas, instituições e comunidades. Utilizando-se das palavras de Paulo Freire (2016, p. 253), esperamos que as discussões e práticas potencializadas pelo presente texto possam contribuir de alguma forma para a "criação de um mundo em que seja menos difícil amar”.

\section{Referências}

Alonso, A. (2009). As teorias dos movimentos sociais: Um balanço do debate. Lua Nova, (76), 49- 86. https://doi.org/ $10.1590 /$ S0102-64452009000100003

Berkowitz, L. (1972). Frustrations, comparisons, and other sources of emotion aroused as contributors to social unrest. Journal of Social Issues, 28(1), 77-92. https://doi.org/10.1111/j.1540-4560.1972.tb00005.x

Betim, F. (13 jul. 2021). Promotoras deixam caso Marielle por risco de "interferências externas" nas investigações e preocupam familiares. El País Brasil. https://brasil.elpais.com/noticias/caso-marielle-franco/

Blumer, H. (1969). Social movements. In B. McLaughlin (Org.), Studies in social movements: A social psychological perspective (pp. 8-24). Free Press.

Boschi, R. (1987). A arte da associação. Política de base e democracia no Brasil. Iuperj; Vértice.

Camino, L., Silva, E. A., \& Souza, S. M. (1998). Primeiros passos para a elaboração de um modelo psicossociologico do comportamento eleitoral: Estudo dos eleitores de João Pessoa na campanha de 1992. Estudos em Psicologia, 3(1), 7-33. https://doi.org/10.1590/S1413-294X1998000100002 
Camino, L., Torres, A. R., \& Costa, J. B. (1995). Voto, identificación partidária, identidad social y construccion de la ciudadania. In O. D’Adamo, V. G. Beaudoux \& M. Montero (Orgs.), Psicologia de la acción política (pp. 129-142). Paidos.

Campos, A. M., Medeiros, J., \& Ribeiro, M. M. (2016). Escolas de luta. Veneta.

Eyerman, R., \& Jamison, A. (1991). Social movements: A cognitive approach. Pennsylvania State University Press.

Fillieule, O. (1997). Stratégies de la rue: Les Manifestations en France. Presses de Sciences Po.

Freire, P. (2016). Pedagogia do oprimido. Paz e Terra.

Gamson, W. A. (1992). Talking politics. University of Cambridge Press.

Gurr, T. R. (1970). Why men rebel. Princeton University Press.

Harvey, D. (Org.). (2013). Cidades rebeldes: Passe livre e as manifestações que tomaram as ruas do Brasil. Boitempo.

Hoffer, E. (1951). The true believer: Thoughts on the nature of mass movements. Harper and Row.

Instituto de Pesquisas Datafolha. (2018). Avaliação do presidente Michel Temer: PO813964: 06 e 07/06/2018. http:// media.folha.uol.com.br/datafolha/2018/06/11/9a5v4a315iea5cba3o0taf8ebfm3e8r053cfd7b52a88b8at.pdf

Jasper, J. M. (2011). Emotions and Social Movements: Twenty Years of Theory and Research. Annual Review of Sociology, 37(1), 285-303. https://doi.org/10.1146/annurev-soc-081309-150015

Kelly, C., \& Breinlinger, S. (1996). The social psychology of collective action. Taylor and Francis.

Klandermans, B. (1984). Mobilization and participation: social-psychological expansions of resource mobilization theory. American Sociological Review, 49(5), 583-600. https://doi.org/10.2307/2095417

Klandermans, B. (1997). The social psychology of protest. Blackwell Publishers.

Klandermans, B. (2015). A oferta e a demanda da participação: os correlatos psico-sociais a participação nos movimentos sociais. In A. S. Silva \& F. Correa, No interstício das disciplinaridades: a psicologia política (pp. 123-173). Prismas.

Klandermans, B., \& Oegema, D. (1987). Potentials, networks, motivations, and barriers: Steps towards participation in social movements. American sociological review, 519-531.

Klandermans, B., Sabucedo, J. M., Rodriguez, M., \& Weerd, M. D. (2002). Identity processes in collective action participation: Farmers' identity and farmers' protest in the Netherlands and Spain. Political Psychology, 23(2), 235-251. https://doi.org/10.1111/0162-895X.00280

Klandermans, B., \& de Weerd, M. (2000). Group identification and political protest. In S. Stryker, T. J. Owens \& R. W. White (Eds.), Self, identity, and social movements (pp. 68-90). University of Minnesota Press.

Kornhauser, W. (1959). The politics of mass society. Free Press.

Lane, S. T. M., \& Codo, W. (Orgs.). (2004). Psicologia social: O homem em movimento. Brasiliense.

Lara Junior, N. (2007). Análise psicopolítica da mística do MST: a formação da ideologia político-religiosa. Revista Psicologia Política, 7(13), 143-168.

Lara Junior, N. (2010). A mística do MST como laço social [Tese de doutorado, Pontifícia Universidade Católica de São Paulo]. Repositório PUCSP.

Lara Junior, N., \& Prado, M. A. M. (2004). A mística e a construção da identidade política entre os participantes do Movimento dos Trabalhadores Rurais Sem Terra do Brasil: Um enfoque psicossociológico. Revista Electrónica de Psicología Política, 1(4), 1-30.

Laraña, E., Johnson, H., \& Gusfield, J. R. (Orgs.). (1994). New social movements: From ideology to identity. Temple University Press.

Le Bon, G. (1954). Psicologia das multidões. F. Briguet e Cia.

Maheirie, K. (2002). Música popular, estilo estático e identidade coletiva. Psicologia Política, 2(3), 39-54.

McAdam, D. (1982). Political process and the development of black insurgency, 1930-1970. The University of Chicago Press. 
McCarthy, J. D., \& Zald, M. N. (1977). Resource mobilization and social movements: A partial theory. The American Journal of Sociology, 82(6), 1212-1241.

Morris, A. D., \& Mueller, C. M. (1992). Frontiers in social movement theory. Yale University Press.

Olson, M. (1965). The logic of collective action: Public goods and the Theory of Groups. Harvard University Press.

Orfali, B. (1990). L'Adhésion au Front National: De la minorité au mouvement social. Kimé.

Ostrom, T. M. (1984). The sovereignty of social cognition. In R. S. Wyer Jr. \& T. K. Srull (Orgs.), Handbook of social cognition (pp. 1-38). Lawrence Erlbaum.

Partido Socialismo e Liberdade. (15 mar. 2018). Confira agenda de atos em memória de Marielle Franco. https:// psol50.org.br/confira-agenda-de-atos-em-memoria-de-marielle-franco/

Pinto, C. R. J. (2017). A trajetória discursiva das manifestações de rua no Brasil (2013-2015). Lua Nova, 100, 119-153. https://doi.org/10.1590/0102-119153/100

Polletta, F. E., \& Jasper, M. J. (2001). Collective identity and social movements. Annual Review of Sociology, 27, 283-305. https://doi.org/10.1146/annurev.soc.27.1.283

Rodrigues, C. M. L. R. (2002). "Daqui não saio, daqui ninguém me tira": Estudo de caso do MTST (Movimento dos Trabalhadores Sem-Teto), para além da dicotomia entre identidade e estratégia [Dissertação de mestrado, Universidade Federal de Pernambuco]. Attena - Repositório Digital da UFPE.

Roggeband, C., \& Klandermans, B. (Eds.). (2017). Handbook of social movements across disciplines. Springer.

Rosa, L. A. (2017). Lutar, verbo transitivo: Uma perspectiva psicopolítica sobre militantes e educadores do MST. Editora Prismas.

Runciman,W.G. (1966). Relative deprivation and social justice:Astudy of attitudes to social inequality in twentieth-century England. University of California Press.

Sader, E. (1988). Quando novos personagens entraram em cena. Paz e Terra.

Saldaña, P., \& Lazzeri, T. (15 dez. 2016). Ocupações de escolas opõem pais e alunos em SP, diz pesquisa Datafolha. Folha de S.Paulo. https://wwwl.folha.uol.com.br/educacao/2016/12/1841586-ocupacoesde-escolas-opoem-pais-e-alunos-em-sp-diz-pesquisa-datafolha.shtml

Sandoval, S. A. M. (2001). The crisis of the Brazilian labor movement and the emergence of alternative forms of working-class contention in the 1990s. Revista Psicologia Política, 1(1), 173-195.

Silva, A. S. (2008). Luta, resistência e cidadania: Uma análise psicopolítica dos Movimentos e Paradas do Orgulho LGBT. Juruá.

Silva, A. S., \& Correa, F. (Orgs.). (2015). No interstício das disciplinaridades: A psicologia política. Prismas.

Simon, B., Loewy, M. I., Stürmer, S., Weber, U., Freytag, P., Habig, C., Kampmeier, C., \& Spahlinger, P. (1998). Collective Identification and Social Movement Participation. Journal of Personality and Social Psychology, 74(3), 646-658. https://doi.org/10.1037/0022-3514.74.3.646

Smelser, N. J. (1971). Theory of collective behavior. The Free Press.

Tarrow, S. (2009). O poder em movimento: Movimentos sociais e confronto político. Editora Vozes.

Tilly, C. (1978). From mobilization to revolution. Addison-Wesley Pub.

Tilly, C. (2004). Social movements, 1768-2004. Paradigm Publishers.

Toch, H. (1966). The social psychology of social movements. Methuen.

Tristan, A. (1987). Au front. Gallimard.

Van Stekelenburg, J., \& Klandermans, B. (2017). Individuals in movements: A social psychology of contention. In C. Roggeband \& B. Klandermans (Eds.), Handbook of social movements across disciplines (pp. 103-139). Springer.

Van Stekelenburg, J., \& Klandermans, B. (2010). Radicalization. In A. E. Azzi, X. Chryssochoou, B. Klandermans \& B. Simon (Eds.), Identity and participation in culturally diverse societies (pp. 181-194). Wiley-Blackwell.

Van Troost, D. M. M., Van Stekelenburg, J., \& Klandermans, P. G. (2013). Emotions of protest. In N. Demertzis (Ed.), Emotions in politics: The affect dimension in political tension (pp. 186-203). Palgrave. 


\section{Leandro Amorim Rosa}

Professor da Universidade Federal do Acre (UFAC), Rio Branco -AC, Brasil. PesquisadorVisitante na Vrije Universiteit Amsterdam (2018), Amsterdã - Holanda do Norte, Holanda. Compõe a Rede de Saúde Mental junto ao Movimento dos Trabalhadores Rurais Sem Terra (MST).

E-mail: leandro.rosa@ufac.br

(1) https://orcid.org/0000-0002-0742-2359

\section{Bert Klandermans}

Professor do Departamento de Sociologia daVrije Universiteit Amsterdam (VU), Amsterdã-Holanda do Norte, Holanda. E-mail: p.g.klandermans@vu.nl

(1) https://orcid.org/0000-0002-8477-5780

Endereço para envio de correspondência:

Universidade Federal do Acre, Centro de Filosofia e Ciências Humanas. Rodovia BR 364, Km 04, Distrito Industrial. CEP: 69920-900. Rio Branco - AC. Brasil

Recebido 22/01/2020

Aceito 04/05/2021

Received $01 / 22 / 2020$

Approved 05/04/2021

Recibido 22/01/2020

Aceptado 04/05/2021

Como citar: Rosa, L. A., \& Klandermans, B. (2022). Psicologia social do protesto: Um panorama teórico a partir da realidade brasileira. Psicologia: Ciência e Profissão, 42, 1-15. https://doi.org/10.1590/1982-3703003233201

How to cite: Rosa, L. A., \& Klandermans, B. (2022). Social psychology of protest: A theoretical panorama based on Brazilian reality. Psicologia: Ciência e Profissão, 42, 1-15. https://doi.org/10.1590/1982-3703003233201

Cómo citar: Rosa, L. A., \& Klandermans, B. (2022). Psicología social de la protesta: Un panorama teórico desde la realidad brasileña. Psicologia: Ciência e Profissão, 42, 1-15. https://doi.org/10.1590/1982-3703003233201 